\title{
Asymmetric Dimethylarginine and the Effect of Folate Substitution in Children with Familial Hypercholesterolemia and Diabetes Mellitus Type 1
}

\author{
P. JEHLIČKA ${ }^{1}$, F. STOŽICKÝ ${ }^{1}$, O. MAYER JR. ${ }^{2}$, J. VARVAŘOVSKÁ $^{1}$, J. RACEK $^{3}$, \\ L. TREFIL ${ }^{3}$, K. SIALA ${ }^{1}$ \\ ${ }^{1}$ Department of Pediatrics, ${ }^{2}$ Second Department of Internal Medicine, ${ }^{3}$ Department of Clinical \\ Biochemistry and Hematology, Charles University in Prague, Faculty of Medicine in Pilsen, \\ Czech Republic
}

Received October 5, 2007

Accepted January 11, 2008

On-line April 1, 2008

\begin{abstract}
Summary
A recently discussed cardiovascular risk factor, asymmetric dimethylarginine (ADMA), is known to act as an endogenous inhibitor of endothelial nitric oxide synthase. The aim of this study was to establish 1 ) the relationship between ADMA and ultrasonographically or biochemically determined endothelial dysfunction in children, and 2) the effect of folate supplementation on these parameters. The study cohort included 32 children with familial hypercholesterolemia (FH), 30 with diabetes mellitus type 1 (DM1) and 30 age-matched healthy children as the control group. Furthermore, twenty-eight randomly selected $\mathrm{FH}$ and DM1 children were re-examined after 3-months supplementation with folic acid. Baseline levels of ADMA and oxidized low density lipoproteins (oxLDL) were significantly higher in FH group than in DM1 and healthy children. Children in DM1 group had significantly lower concentration of homocysteine, but ADMA levels were normal. Folic acid supplementation significantly lowered homocysteine and hsCRP levels in both FH and DM1 group; however, ADMA and oxLDL concentrations remained unaltered. In conclusion, ADMA and oxLDL appear to be associated with endothelial dysfunction in children with $\mathrm{FH}$. Administration of folic acid did not influence these markers in both FH and DM1 children.
\end{abstract}

\section{Key words}

ADMA - Children - Endothelial dysfunction - Folic acid • Homocysteine

\section{Corresponding author}

P. Jehlička, Department of Pediatrics, Charles University in Prague, Faculty of Medicine in Pilsen, Alej Svobody 80, 30460 Plzeň, Czech Republic. E-mail: JEHLICKA@fnplzen.cz

\section{Introduction}

The concept of early prevention of cardiovascular disease in childhood could be a potentially valuable tool in reducing cardiovascular mortality and morbidity in adulthood. Tackling risk factors in childhood may be more effective than dealing with established cardiac disease in adulthood.

A recently discussed cardiovascular risk factor, asymmetric dimethylarginine (ADMA), acts as endogenous inhibitor of endothelial nitric oxide synthase. ADMA is closely linked to homocysteine metabolism and its increased level may affect predominantly endothelium-dependent vasodilatation (Goonasekera et al. 2000, Yilmaz et al. 2006). It has been reported, that supplementation with folic acid lowers ADMA levels and consequently improves endothelial function in children with chronic renal insufficiency (Bennett-Richards et al. 2002).

Flow-mediated dilation (FMD) represents the most commonly approved method for quantifying endothelial function ultrasonographically. This method assesses the endothelium-dependent vasodilative response to increased shear stress following transitory 
mechanical occlusion. Demanding requirements on technical equipment and the unpredictable biological variability of FMD are limiting factors for obtaining reliable results in clinical practice (Hijmering et al. 2001). The deceleration index (DI) is an ultrasonographic method based on a decrease in the velocity gradient between the first and second minute of post-occlusion (Jehlička and Mayer 2005); this reflects the endotheliumdependent vasodilative response on the dopplerometric principle. DI is not technically demanding; thus potentially presenting an alternative, more time- and costeffective approach than FMD.

The aim of this study was to establish the relationship between ADMA and ultrasonographically and biochemically determined markers of endothelial dysfunction (ED) in children with FH and DM1. Furthermore, we assessed the effect of folate supplementation on these parameters.

\section{Material and Methods}

Thirty two children were enrolled into the $\mathrm{FH}$ group (12 females/20 males, mean age 14.7 \pm 2.9 years). Besides dietary interventions in all children, six patients were treated with resins, six with statins and six with a combination of statin and ezetimibe. DM 1 group consisted from 30 children (12 females/18 males, mean age $14.6 \pm 1.7$ years); the mean duration of diabetes was $4.4 \pm 2$ years. None of these patients had evidence of retinopathy or microalbuminuria. The control group consisted of 30 age-matched healthy children (18 females/12 males, mean age $15.1 \pm 1.7$ years).

Eighteen children from $\mathrm{FH}$ and 10 children from DM 1 group were randomly selected for the interventional part of the study. These children were supplemented with folic acid $5 \mathrm{mg}$ /day for 3 months. After the intervention period, the effect of the treatment on biochemical and ultrasonographic markers of ED was assessed. No changes in concomitant therapy were made within this period.

In all children anthropometric data were obtained according to standardized protocol. Blood samples were drawn after overnight fasting. Plasma concentrations of total cholesterol (TC), high-density lipoprotein cholesterol (HDL) and triglycerides (TG) were assessed by photometric enzymatic methods (Abbott, Wiesbaden, Germany), low-lipoprotein cholesterol (LDL) was calculated according to Friedwald formula. Total homocysteine (Hcy) concentration was measured using an enzymatic photometric method from Carolina (Brea, CA, USA), glycated hemoglobin (HbA1c) by Ionex Chromatography using a Tosoh G7 analyzer (Tosoh Corporation, Tokyo, Japan), and folate using the chemiluminescent immunoassay on Architect i2000 analyzer, (Abbott, Chicago, IL, USA). The plasma level of oxLDL was assessed by ELISA method (Mercodia, Uppsala, Sweden). Malondialdehyde (MDA) was measured as thiobarbituric acid-reactive substances (TBARS) with modification by Jentzsch et al. (1996), hsCRP by the immunoturbidimetric assay (Orion Diagnostica Oy, Espoo, Finland) and asymmetric dimethylarginine (ADMA) was determined by ELISA assay (DLD Diagnostika, Hamburg, Germany). All photometric and turbidimetric variables were measured using Olympus AU 400 analyzer (Olympus, Mishima, Japan). AUTO-EIA II microplate reader from Labsystems Oy (Espoo, Finland) was used for evaluation of ELISA methods.

Ultrasonographic examinations were performed by a single examiner during the same period of the day to eliminate the diurnal fluctuation. Both FMD and DI were measured using high-resolution ultrasound system (GE system FIVE) with a linear probe $7-10 \mathrm{MHz}$ fixed on the patient's forearm above the right brachial artery. FMD and DI were assessed at baseline and then after one month to ascertain intra-individual variability with respect to ovarian cycles in girls. Coefficients of variation of FMD and DI were expressed as [median (interquartile range)].

Statistical analysis of the data was done using STATISTICA 8 software. The significance of differences among specific groups (i.e. FH, DM1 and controls) was evaluated using the Mann-Whitney $U$ test, whereas the intra-individual treatment response in observed variables were assessed using the Wilcoxon paired test.

\section{Results}

The basic characteristics of these three groups are presented in Table 1. There were no statistical differences in age, gender, body mass index and blood pressure among the study groups. As expected, FH children had significantly higher total cholesterol, LDL and oxidized LDL, while DM1 children exhibited higher HbAlc levels than control subjects. ADMA concentrations were higher in both FH and DM1 children than in controls; however, this difference reached statistical significance only in the FH group. Both FH and 
Table 1. Baseline characteristics of the study cohort.

\begin{tabular}{|c|c|c|c|}
\hline & FH & DM 1 & Controls \\
\hline n (boys/girls) & $32(20 / 12)$ & $30(18 / 20)$ & $30(12 / 18)$ \\
\hline Age [years] & $14.7 \pm 2.9$ & $14.6 \pm 1.7$ & $15.1 \pm 1.7$ \\
\hline Body mass index $\left[\mathrm{kg} / \mathrm{m}^{2}\right]$ & $22.0 \pm 4.1$ & $21.9 \pm 3.4$ & $20.2 \pm 2.4$ \\
\hline Systolic BP [mmHg] & $122.3 \pm 10.7$ & $121.9 \pm 11.2$ & $120.1 \pm 9$ \\
\hline Diastolic BP [mmHg] & $70.9 \pm 9.1$ & $72.6 \pm 9.4$ & $69.5 \pm 9.5$ \\
\hline Total cholesterol [mmol/l] & $5.46 \pm 1.48 * * *$ & $4.07 \pm 1.0$ & $3.68 \pm 0.74$ \\
\hline LDL cholesterol [mmol/l] & $3.58 \pm 1.45 * * *$ & $2.09 \pm 0.94$ & $1.90 \pm 0.92$ \\
\hline HDL cholesterol [mmol/l] & $1.46 \pm 0.39$ & $1.62 \pm 0.59$ & $1.48 \pm 0.62$ \\
\hline Triglycerides [mmol/l] & $1.13 \pm 0.59$ & $0.98 \pm 0.72$ & $0.87 \pm 0.3$ \\
\hline$o x L D L[m U / l]$ & $73.69 \pm 24.9 * * *$ & $51.71 \pm 23.29$ & $55.7 \pm 30.47$ \\
\hline $\operatorname{HbAlc}[\%]$ & $3.44 \pm 0.25$ & $7.48 \pm 1.94 * * *$ & $3.43 \pm 0.33$ \\
\hline Homocysteine $[\mu \mathrm{mol} / \mathrm{l}]$ & $7.88 \pm 3.37$ & $5.42 \pm 1.9 * * *$ & $8.60 \pm 3.86$ \\
\hline Folate $[\mu \mathrm{g} / l]$ & $10.71 \pm 3.28$ & $11.16 \pm 2.98$ & $9.82 \pm 2.70$ \\
\hline$h s C R P[\mathrm{mg} / \mathrm{ll}]$ & $1.02 \pm 0.98 * * *$ & $1.38 \pm 1.37 * * *$ & $0.76 \pm 1.55$ \\
\hline ADMA [umol/l] & $0.94 \pm 0.18 * * *$ & $0.84 \pm 0.18$ & $0.77 \pm 0.14$ \\
\hline$F M D[\%]$ & $7.3 \pm 7.8$ & $7.3 \pm 7.0$ & $6.3 \pm 3.6$ \\
\hline$D I[\%]$ & $19.8 \pm 9$ & $16.5 \pm 14$ & $21.5 \pm 9.4$ \\
\hline
\end{tabular}

Data are mean \pm S.D. ${ }^{* * *} \mathrm{p}<0.001 ; \mathrm{FH}$ or DM1 vs. controls. LDL - low density lipoproteins; HDL - high density lipoproteins; HbA1c glycated hemoglobin; ADMA - asymmetric dimethylarginine; oxLDL - oxidized low density lipoproteins; hsCRP - high selective C-reactive protein; FMD - flow-mediated dilation; DI - deceleration index.

DM1 children had significantly higher hsCRP than control subjects. Interestingly, DM1 children had significantly lower Hcy concentrations. No significant differences between FH, DM1 and controls were found in their ultrasonographic parameters (FMD and DI). Coefficients of variation of FMD and DI were 1.77 (0.50$1.79)$ and $1.02(0.68-1.53)$, respectively.

The associations between ADMA and ultrasonographic markers of ED are shown in Table 2 where potentially confounding factors are also taken into account. The association between ADMA and ultrasonographic ED surrogates did not reach statistical significance.

The effect of 3 months of folate substitution ( $5 \mathrm{mg}$ folate daily) on ADMA and other ED surrogates is given in Table 3. Folate supplementation resulted in a significant increase in plasma folate levels, and a decrease in homocysteine and hsCRP levels. On the other hand, ADMA, oxLDL levels and ultrasonographic surrogates of ED remained unaltered. This treatment response was independent of the current treatment strategy (dietary regimen vs. resin vs. statin) in FH children. Similarly in DM1 children the treatment response was independent of HbA1c levels (data not shown).

\section{Discussion}

In our study we established elevated ADMA concentrations in children with $\mathrm{FH}$, but not in those with DM1. We were unable to demonstrate an association between ADMA and ultrasonographic surrogates of endothelial dysfunction. Furthermore, neither ADMA nor ultrasonographic markers appeared to respond to folate administration. Significantly higher oxLDL plasma levels in the FH patients appeared to reflect the elevated oxidative stress in this group, but this association was not observed in children with DM1. Elevated hsCRP concentrations were demonstrated in both FH and DM1 groups. These levels declined following the administration of folic acid in accordance with previously reported observations (Picardi et al. 2007). Nevertheless, the low specificity of hsCRP should be taken into account and considered as a supportive marker of ED only. Lowering homocysteine levels using folic acid has been shown to result in a decrease of ADMA levels in adults (Holven et al. 2003). A protective effect of folic acid on endothelial dysfunction in children was ascertained in previously published studies (Wiltshire et al. 2002, Peňa et al. 2004). We were unable to confirm this relationship, 
Table 2. Ultrasonographic markers of endothelial dysfunction and other parameters of ADMA tertiles.

\begin{tabular}{|c|c|c|c|c|}
\hline ADMA tertiles & $\begin{array}{c}\text { First tertile } \\
{[<0.76 \mu \mathrm{mol} / \mathrm{l}]}\end{array}$ & $\begin{array}{c}\text { Second tertile } \\
{[0.76-0.89 \mu \mathrm{mol} / \mathrm{l}]}\end{array}$ & $\begin{array}{c}\text { Third tertile } \\
{[>0.90 \mu \mathrm{mol} / \mathrm{l}]}\end{array}$ & $\begin{array}{l}p \text { for } \\
\text { trend }\end{array}$ \\
\hline$n$ (\% of females) & $31(54.8)$ & $30(43.3)$ & $30(66.7)$ & 0.89 \\
\hline age [years] & $15.7 \pm 0.40$ & $14.9 \pm 0.32$ & $13.6 \pm 0.39$ & 0.21 \\
\hline Body mass index $\left[\mathrm{kg} / \mathrm{m}^{2}\right]$ & $22.0 \pm 0.61$ & $21.1 \pm 0.56$ & $21.1 \pm 0.73$ & 0.87 \\
\hline Systolic BP [mmHg] & $123.9 \pm 1.90$ & $120.4 \pm 1.74$ & $120.0 \pm 1.96$ & 0.25 \\
\hline Diastolic BP [mmHg] & $72.6 \pm 1.62$ & $70.0 \pm 1.64$ & $70.3 \pm 1.86$ & 0.90 \\
\hline LDL cholesterol [mmol/l ] & $2.21 \pm 0.23$ & $2.68 \pm 0.26$ & $2.79 \pm 0.24$ & 0.66 \\
\hline$o x L D L[m U / l]$ & $58.6 \pm 4.92$ & $66.5 \pm 6.19$ & $58.2 \pm 4.30$ & 0.92 \\
\hline $\mathrm{HbAlC}[\%]$ & $5.25 \pm 0.49$ & $4.87 \pm 0.40$ & $4.17 \pm 0.27$ & 0.09 \\
\hline Homocysteine [ $\mu \mathrm{mol} / \mathrm{l}]$ & $7.10 \pm 0.55$ & $6.88 \pm 0.46$ & $7.92 \pm 0.80$ & 0.66 \\
\hline Folate $[\mu \mathrm{g} / \mathrm{l}]$ & $10.7 \pm 0.56$ & $10.5 \pm 0.47$ & $10.6 \pm 0.63$ & 0.74 \\
\hline$h s C R P[\mathrm{mg} / \mathrm{l}]$ & $1.03 \pm 0.21$ & $1.12 \pm 0.31$ & $1.01 \pm 0.19$ & 0.17 \\
\hline$F M D[\%]$ & $8.18 \pm 1.06$ & $6.49 \pm 1.21$ & $6.25 \pm 1.25$ & 0.07 \\
\hline$D I[\%]$ & $20.77 \pm 2.20$ & $18.6 \pm 1.94$ & $18.1 \pm 1.95$ & 0.74 \\
\hline
\end{tabular}

Data are mean \pm S.D., p value by Kruskal-Wallis ANOVA. LDL - low density lipoproteins; HbA1c - glycated hemoglobin; ADMA asymmetric dimethylarginine; oxLDL - oxidized low density lipoproteins; hsCRP - high selective C-reactive protein; FMD - flowmediated dilation; DI - deceleration index.

Table 3. Effect of folic acid supplementation on ADMA and endothelial dysfunction surrogates.

\begin{tabular}{|c|c|c|c|c|}
\hline & \multicolumn{2}{|c|}{ FH $(n=18)$} & \multicolumn{2}{|c|}{ DM1 $(n=10)$} \\
\hline & Baseline & After 3 months & Baseline & After 3 months \\
\hline Folate $[\mu \mathrm{g} / \mathrm{l}]$ & $10.47 \pm 3.55$ & $18.01 \pm 1.66^{* * *}$ & $8.77 \pm 2.31$ & $16.94 \pm 3.63 * * *$ \\
\hline Homocysteine $[\mu \mathrm{mol} / \mathrm{l}]$ & $9.14 \pm 3.81$ & $5.15 \pm 1.89 * * *$ & $6.42 \pm 2.09$ & $4.54 \pm 1.15^{* * *}$ \\
\hline$A D M A[\mu \mathrm{mol} / l]$ & $0.94 \pm 0.22$ & $0.87 \pm 0.35$ & $0.81 \pm 0.13$ & $0.87 \pm 0.22$ \\
\hline$o x L D L[m U / l]$ & $63.36 \pm 18.9$ & $65.05 \pm 20.8$ & $43.35 \pm 10.7$ & $40.86 \pm 11.11$ \\
\hline$h s C R P[\mathrm{mg} / \mathrm{l}]$ & $1.15 \pm 0.96$ & $0.60 \pm 0.71 * *$ & $1.57 \pm 1.33$ & $0.58 \pm 0.49^{*}$ \\
\hline$F M D[\%]$ & $7.4 \pm 5.9$ & $4.7 \pm 4.4$ & $4.07 \pm 3.71$ & $4.78 \pm 6.48$ \\
\hline$D I[\%]$ & $19.4 \pm 7.5$ & $21.1 \pm 12.9$ & $17.50 \pm 8.84$ & $25.18 \pm 12.76$ \\
\hline
\end{tabular}

Data are mean \pm S.D., $* * * \mathrm{p}<0.001 ; * * \mathrm{p}<0.01 ; * \mathrm{p}<0.05$. ADMA - asymmetric dimethylarginine; oxLDL - oxidized low density lipoproteins; hsCRP - high selective C-reactive protein; FMD - flow-mediated dilation; DI - deceleration index.

and thus the clinical interaction between folate, homocysteine and ADMA is indeed controversial. FH subjects with normal homocysteine levels demonstrated significantly higher ADMA levels compared with healthy children. Furthermore, DM1 subjects demonstrated significantly lower homocysteine levels compared with both FH and controls - probably due to the increased filtration fraction (Raes et al. 2007). In spite of this, the DM1 group demonstrated normal ADMA levels. In addition, supplementation with folate resulted in a significant reduction of homocysteine in the FH and DM1 groups, though ADMA concentration remained elevated.
In accordance with previously published studies in children (Järvisalo et al. 2004), the administration of folate did not lower the oxLDL levels in our subjects. Our findings regarding folate are also in accordance with a published study in adults (Spoelstra-de Man et al. 2006) as well as with recently published studies that failed to demonstrate a protective effect of folic acid on cardiovascular risk (Lonn et al. 2006, Bonaa et al. 2006).

The sensitivity of both ultrasonographic methods was low - neither FMD nor DI were able to significantly distinguish differences between the studied groups. Despite adhering to the methodical recommendations 
(Corretti et al. 2002) for measurement of FMD and using a sufficient time interval for detection of the maximal postocclusive diameter in early and late responders (Järvisalo et al. 2002), we were unable to achieve reliable results. The most important reason for this could be the high biological variability of FMD (De Roos et al. 2003) and DI.

\section{Conclusions}

In the conducted study, plasma levels of ADMA and oxLDL were significantly elevated in children with FH and appeared to be associated with ED in children with FH. This finding was not observed in children with DM1. Supplementation with folic acid did not influence ADMA and oxLDL concentrations, despite having a significant lowering effect on homocysteine and hsCRP in both FH and DM1 groups. The complicated relationship between homocysteine and ADMA is further accentuated by the fact that the significantly lower homocysteine levels in children with DM1 did not correlate with lower ADMA levels in this group. Further work is required to determine the clinical interaction between homocysteine, folic acid and ADMA. The low sensitivity and high biological variability of FMD and DI used in this study were disappointing. Nevertheless, the combination of ADMA, oxLDL and advanced imaging methods may still play an important role in the prediction of cardiovascular risk and future treatment strategies in children with a high risk of premature manifestation of atherosclerosis.

\section{Conflict of Interest}

There is no conflict of interest.

\section{Acknowledgements}

Supported by an IGA grant from the Czech Ministry of Health, Nr. 8455-3/ 2005. We thank Professor MUDr. Josef Hyánek, DrSc. for referring his patients.

\begin{abstract}
Abbreviations
ADMA - asymmetric dimethylarginine, BMI - body mass index, BP - blood pressure, DI - deceleration index, DM1 - diabetes mellitus type 1, ED - endothelial dysfunction, FH - familial hypercholesterolemia, FMD flow-mediated dilation, HbA1c - glycated hemoglobin, HDL - high density lipoproteins, hsCRP - high selective C-reactive protein, LDL - low density lipoproteins, oxLDL - oxidized low density lipoproteins, MDA malondialdehyde, NOS - nitric oxide synthase.
\end{abstract}

\section{References}

BENNETT-RICHARDS K, KATTENHORN M, DONALD A, OAKLEY G, VARGHESE Z, REES L, DEANFIELD JE: Does oral folic acid lower total homocysteine levels and improve endothelial function in children with chronic renal failure? Circulation 105: 1810-1815, 2002.

BØNAA KH, NJØLSTAD I, UELAND PM, SCHIRMER H, TVERDAL A, STEIGEN T, WANG H, NORDREHAUG JE, ARNESEN E, RASMUSSEN K; NORVIT TRIAL INVESTIGATORS: Homocysteine lowering and cardiovascular events after acute myocardial infarction. $N$ Engl J Med 354: 1578-1588, 2006.

CORRETTI MC, ANDERSON TJ, BENJAMIN EJ, CELERMAJER D, CHARBONNEAU F, CREAGER MA, DEANFIELD J, DREXLER H, GERHARD-HERMAN M, HERRINGTON D, VALLANCE P, VITA J, VOGEL R: International Brachial Artery Reactivity Task Force. Guidelines for the ultrasound assessment of endothelial-dependent flow-mediated vasodilation of the brachial artery: a report of the International Brachial Artery Reactivity Task Force. J Am Coll Cardiol 39: 257-265, 2002.

DE ROOS NM, BOTS ML, SCHOUTEN EG, KATAN MB: Within-subject variability of flow-mediated vasodilation of the brachial artery in healthy men and women: implications for experimental studies. Ultrasound Med Biol 29: 401-406, 2003.

GOONASEKERA CD, SHAH V, REES DD, DILLON MJ: Vascular endothelial cell activation associated with increased plasma asymmetric dimethyl arginine in children and young adults with hypertension: a basis for atheroma? Blood Press 9: 16-21, 2000.

HIJMERING ML, STROES ES, PASTERKAMP G, SIEREVOGEL M, BANGA JD, RABELINK TJ: Variability of flow mediated dilation: consequences for clinical application. Atherosclerosis 157: 369-373, 2001. 
HOLVEN KB, HAUGSTAD TS, HOLM T, AUKRUST P, OSE L, NENSETER MS: Folic acid treatment reduces elevated plasma levels of asymmetric dimethylarginine in hyperhomocysteinaemic subjects. Br J Nutr 89: 359363, 2003.

JÄRVISALO MJ, RONNEMAA T, VOLANEN I, KAITOSAARI T, KALLIO K, HARTIALA JJ, IRJALA K, VIIKARI JS, SIMELL O, RAITAKARI OT: Brachial artery dilatation responses in healthy children and adolescents. Am J Physiol 282: H87-H92, 2002.

JÄRVISALO MJ, LEHTIMAKI T, RAITAKARI OT, Determinants of arterial nitrate-mediated dilatation in children: role of oxidized low-density lipoprotein. endothelial function. and carotid intima-media thickness. Circulation 109: 2885-2889, 2004.

JEHLIČKA P, MAYER O JR: Pilot study of the noninvasive assessment of endothelial dysfunction by postocclusion dopplerometry velocity curves analysis in arteria brachialis. (in Czech) Cas Lek Cesk 144: 43-46, 2005.

JENTZSCH AM, BACHMANN H, FURST P, BIESALSKI HK: Improved analysis of malondialdehyde in human body fluids. Free Radic Biol Med 20: 251-256, 1996.

LONN E, YUSUF S, ARNOLD MJ, SHERIDAN P, POGUE J, MICKS M, MCQUEEN MJ, PROBSTFIELD J, FODOR G, HELD C, GENEST J JR: Heart Outcomes Prevention Evaluation (HOPE) 2 Investigators. Hocysteine lowering with folic acid and B vitamins in vascular disease. N Engl J Med 354: 1567-1577, 2006.

PEÑA AS, WILTSHIRE E, GENT R, HIRTE C, COUPER J: Folic acid improves endothelial function in children and adolescents with type 1 diabetes. J Pediatr 144: 500-504, 2004.

PICARDI A, VALORANI MG, VESPASIANI GENTILUCCI U, MANFRINI S, CIOFINI O, CAPPA M, GUGLIELMI C, POZZILLI P: Raised C-reactive protein levels in patients with recent onset type 1 diabetes. Diabetes Metab Res Rev 23: 211-214, 2007.

RAES A, DONCKERWOLCKE R, CRAEN M, HUSSEIN MC, VANDE WALLE J: Renal hemodynamic changes and renal functional reserve in children with type I diabetes mellitus. Pediatr Nephrol 22: 1903-1909, 2007.

SPOELSTRA-DE MAN AM, TEERLINK T, BROUWER CB, RAUWERDA JA, STEHOUWER CD, SMULDERSY M: No effect of B vitamins on ADMA levels in patients at increased cardiovascular risk. Clin Endocrinol (Oxf) 64: 495-501, 2006.

WILTSHIRE EJ, GENT R, HIRTE C, PENA A, THOMAS DW, COUPER JJ: Endothelial dysfunction relates to folate status in children and adolescents with type 1 diabetes. Diabetes 51: 2282-2286, 2002.

YILMAZ MI, SAGLAM M, CAGLAR K, CAKIR E, SONMEZ A, OZGURTAS T, AYDIN A, EYILETEN T, OZCAN O, ACIKEL C, TASAR M, GENCTOY G, ERBIL K, VURAL A, ZOCCALI C: The determinants of endothelial dysfunction in CKD: oxidative stress and asymmetric dimethylarginine. Am J Kidney Dis 47: 42$50,2006$. 